\title{
UM OLHAR SOBRE A LEGISLAÇÃO PROFISSIONAL DE BIBLIOTECONOMIA E SUA RELAÇÃO COM AS BIBLIOTECAS ESCOLARES
}

\author{
Ediane Toscano Galdino de Carvalho \\ Professora do Departamento em Ciência da Informação - UFPB \\ Mestre em Ciência da Informação \\ edianetgc@gmail.com
}

Resumo

\begin{abstract}
Apresenta uma revisão de literatura sobre a legislação de bibliotecários do Brasil e traz a discussão sobre a legislação que possibilita a efetivação de realização de concurso público para o estado da Paraíba e para a cidade de João Pessoa, inserindo neste contexto a Lei 12.244/10 que trata da universalização das bibliotecas escolares. A legislação bibliotecária é fundamental para garantir o efetivo exercício fundamentado nos direitos e deveres dos profissionais.
\end{abstract}

Palavras-chave: Legislação de Biblioteconomia. Lei 12.244/10. Bibliotecário na Paraíba.

\section{INTRODUÇÃO}

Todo e qualquer profissional precisa de uma regulamentação para que seu exercício seja legal e tenha seguridade de seus direitos, mas também de seus deveres. Na área da Biblioteconomia os profissionais são reconhecidos por lei, mas ainda falta muito a ser conquistado, tendo em vista que o reconhecimento pleno de sua importância pela sociedade ainda precisa de muitas lutas, possibilitando o fortalecimento da área e do profissional e garantindo um mercado de trabalho de forma segura.

Esta pesquisa tem como objetivo realizar uma revisão de literatura, buscando reunir o contexto histórico acerca da legislação de Biblioteconomia Brasileira, vinculando a necessidade do profissional estruturado legalmente com relação ao exercício de sua função em bibliotecas escolares a partir da Lei 12.244/10, focando especialmente nos desafios enfrentados no estado da Paraíba e no município de João Pessoa.

Dessa forma, caracteriza-se como uma pesquisa bibliográfica, tendo como base levantamentos em diversas fontes informacionais como: bases de dados, sites de instituições e entidades ligadas à área da biblioteconomia em especial a Federação
Brasileira de Associações de Bibliotecários (FEBAB) e o Conselho Federal de Biblioteconomia (CFB), além de livros e periódicos impressos e online.

Em se tratando de referencial teórico, esta revisão de literatura traz um contexto histórico sobre a legislação bibliotecária perpassando desde a regulamentação da Lei 4.084/62, ao Código de Ética até a Lei 12.244/10 que garante a obrigatoriedade da existência de bibliotecas e bibliotecários em escolas da rede pública e privada.

Busca refletir ainda sobre a legalização do Bibliotecário enquanto profissional de nível superior no Estado da Paraíba e no município de João Pessoa.

\section{CONTEXTUALIZAÇÃO HISTÓRICA DA REGULAMENTAÇÃO DA PROFISSÃO DE BIBLIOTECÁRIO}

A Consolidação das Leis do Trabalho (CLT) foi criada a partir do DecretoLei $\mathrm{n}^{\circ} 5.452$ de 01 de maio de 1943 e sancionada pelo presidente em exercício Getúlio Vargas, cujo objetivo principal é a regulamentação das relações individuais e coletivas do trabalho, previstas na norma legislativa brasileira referente ao direito do trabalho. 
De acordo com a constituição Brasileira 'é livre o exercício de qualquer trabalho, oficio ou profissão, atendidas as qualificações profissionais que a Lei estabelece'. (BRASIL, 1988). Dessa forma, atuar em uma profissão estruturada a partir de leis que regulamentam o exercício do profissional e da profissão, constitui-se como fator relevante para o desenvolvimento das atividades oferecidas, pois podem ser consideradas pela sociedade como profissão e profissional qualificados.

Diante do exposto, surge a necessidade de regulamentação da profissão do bibliotecário, bem como de assegurar seus direitos e interesses como profissional.

Santos (1998) diz que foi a partir da realização do curso de Biblioteconomia da Biblioteca Nacional do Rio de Janeiro em 1911, que o bibliotecário passou a ser identificado formalmente enquanto profissional.

No entanto, o processo de regulamentação da profissão e até mesmo da área, passou por algumas batalhas políticas e culturais até ter algumas iniciativas que foram instrumentos essenciais na construção da legislação da Biblioteconomia Brasileira.

Segundo Job e Oliveira (2006) na década de 50, bibliotecários em especial do Estado de São Paulo, como Laura Garcia Moreno Russo, empenharam-se na luta para reconhecer a profissão de Bibliotecário, surge então, em 1958, a Portaria $\mathrm{n}^{\circ} 162$ do Ministério do Trabalho e Previdência Social (MTPS), que regulamenta a profissão de Biblioteconomia no Serviço Público Federal, incluída no $19^{\circ}$ Grupo das profissões liberais.

Merece destaque para o Projeto de Lei 4.770 que ensejava além da obrigatoriedade de nível superior, a denominação do nome de Bacharel em Ciências Biblioteconômicas. Neste sentido, em 1958 este Projeto foi aprovado pela Câmara dos Deputados, o que foi marco inicial para a regulamentação da Lei 4.084/62. O projeto de Lei teve várias alterações incluindo a alteração do nome de Bacharel em Ciências da Biblioteconomia para Bacharel em Biblioteconomia, como outras alterações, mas houve a conquista da regulamentação da lei 4.084/62, merecendo homenagens aos bibliotecários paulistas daquela época, em especial Laura Garcia
Moreno Russo e a instituição Federação Brasileira de Associações de Bibliotecários (FEBAB) que cada vez mais se tornava mais forte. Nesse sentido, a união da classe bibliotecária e a vontade de legalizar a profissão, levaram a pressionar junto aos congressistas, tendo como Deputado que empenhou esforços, Almino Afonso amigo de muitos bibliotecários. (CASTRO, 2000).

Além do Projeto de Lei mencionado anteriormente, foi efetivado em 1944, no âmbito do governo federal, dois decretos que tiveram influência sobremaneira no Projeto de lei, foram: o Decreto-Lei N. 6.732, de 24 de julho e o Decreto-lei n. 6.440, de 27 de abril. Estes se constituem marcos históricos para a legislação da área da Biblioteconomia no Brasil.

De acordo com Castro (2000, p. 170), o Decreto-lei n. 6.732/44 "determinava as finalidades dos Cursos da Biblioteca Nacional e os dividia em três níveis: Fundamental, Superior e Avulso." Com relação ao Decretolei n. 6.440/44, "juntamente com o Decreto n. 15.395, reorganizou e estabeleceu as normas de adaptação dos cursos de Biblioteconomia, condições de admissão aos mesmos, seriação do currículo escolar, expedição de diplomas e certificados, duração dos cursos, organização didática e escolar”. (CASTRO 2000, p. 170).

Assim, a legalização da profissão de bibliotecário foi constituída a partir de 30 de junho de 1962, com a aprovação da Lei n. 4.084, que dispõe sobre o exercício da profissão de bibliotecário. Foi regulamentada em 16 de agosto de 1965 através do Decreto n. 56.725 .

Dessa forma, oficialmente o reconhecimento da profissão de Bibliotecário no Brasil foi em 30 de Junho de 1962, com a Lei n. 4.084 que é válida até hoje. Dispõe sobre o exercício da profissão destacando:

Art. $\mathbf{1}^{\mathbf{0}}$ A designação profissional de Bibliotecário, a que se refere o quadro das profissões liberais, grupo 19, anexo ao Decreto-lei $\mathrm{n}^{\circ} 5.452$, de $1^{\circ}$ de maio de 1943 (Consolidação das Leis do Trabalho), é privativa dos bacharéis em Biblioteconomia, de conformidade com as leis em vigor. (BRASIL, 1962, p.1). 


\section{Anais do Encontro Paraibano de Biblioteca Escolar}

Esta Lei também esclarece sobre as atribuições do profissional bibliotecário, além de possibilitar a instalação do Conselho Federal e dos Conselhos Regionais de Biblioteconomia (CRB), órgãos estes, responsáveis pela fiscalização da profissão no país.

Em 17 de Agosto de 1966, o Conselho Federal de Biblioteconomia (CFB), publica no Diário Oficial, mais precisamente na seção I, a Resolução CFB n006, de 13 de julho de 1966 , que dispõe sobre o Juramento Profissional do Bibliotecário que diz: "Prometo tudo fazer para preservar o cunho liberal e humanista da profissão de Bibliotecário, fundamentado na liberdade de investigação científica e na dignidade da pessoa humana". (DIÁRIO OFICIAL. 1966, p.2361).

A Lei $n^{\circ} 4.084 / 62$, foi alterada pela Lei $n^{\circ}$ 7.504 de 02 de junho de 1986, no então presidente da República em exercício João Goulart, entre as alterações destaca-se:

Art. $3^{\circ}$ Para o provimento e exercício de cargos técnicos de Bibliotecários e documentalistas, na administração pública autárquica, paraestatal, nas empresas sob intervenção governamental ou nas concessionárias de serviço público, é obrigatória a apresentação do diploma de bacharel em Biblioteconomia respeitados os direitos dos atuais ocupantes efetivos.

\section{Substituído por:}

Art. $3^{\circ}$ Para o provimento e o exercício de cargos técnicos de Bibliotecários, Documentalistas e Técnicos de Documentação, na administração pública federal, estadual ou municipal, autárquica, paraestatal, nas empresas de economia mista ou nas concessionárias de serviços públicos, é obrigatória a apresentação de diploma de Bacharel em Biblioteconomia, respeitados os direitos dos atuais ocupantes." (Redação da Lei $\left.n^{\circ} 7.504 / 02.07 .86\right)$.

Em 26 de junho de 1998, foi promulgada pelo Presidente Fernando Henrique Cardoso, a Lei complementar $\mathrm{n}^{\circ} 9.764$ que dispõe sobre o exercício da profissão de Bibliotecário e dá outras providências, reafirmando a exclusividade do exercício aos portadores de diploma de Bacharel em Biblioteconomia, enfatizando ainda no Cap. II, Art. 4, que "o exercício da profissão de Bibliotecário, no âmbito das pessoas jurídicas de direito público e privado, é privativo dos Bacharéis em Biblioteconomia". (BRASIL, 1998, p.1).

As leis mencionadas deixam claro que apenas os profissionais bibliotecários detentores de diploma reconhecido e registrado em conselho de classe, é que pode exercer a profissão, todavia esse direito não vem sendo respeitado, inclusive dentro da esfera pública onde em alguns casos a função de bibliotecário é desconhecida, sendo exercida por outros profissionais, em especial com desnível de função. Com relação a essa realidade cabe aos conselhos de classe buscar esforços para fiscalizar de maneira consistente e efetivar dos bibliotecários ao seu campo de trabalho.

A partir da regulamentação da profissão de Biblioteconomia, foi pensado em contemplar esta profissão com o código de ética. Dessa forma, $\mathrm{O}$ Conselho Federal de Biblioteconomia no uso de suas atribuições designadas pela Lei 4.084/62, aprova no ano de 1986, o Código de Ética Profissional do Bibliotecário a partir da Resolução CFB N. 327/1986, publicada no Diário Oficial da União em 04 de novembro de 1986. O Código aplica várias normas concernentes a conduta do Bibliotecário, a lealdade e solidariedade com os colegas de Classe, ao tratamento zeloso com os usuários, entre tantas outras. Vale destacar o Art. 6, quando trata da relação dos bibliotecários com a Classe:

a) prestigiar as entidades de Classe, contribuindo sempre que solicitado, para o sucesso de suas iniciativas em proveito da coletividade;

b) zelar pelo prestígio da Classe, pela dignidade profissional e pelo aperfeiçoamento de suas instituições. (BIBLIOTECÁRIO..., 1998, p. 26).

Quando o Bibliotecário ainda não tem o diploma oficialmente registrado nos órgão competentes, ele pode ter o Registro Provisório pelo CRB de sua competência, a partir de atestado de conclusão de curso pela instituição de Ensino Superior que realizou a graduação, além de outros documentos. Esta autorização é legalizada pela Resolução CFB 


\section{Anais do Encontro Paraibano de Biblioteca Escolar}

N. 325/86. Além do Registro Provisório, o CFB também normalizou os processos de transferência de registro a partir da Resolução CFB N. 346/88, uniformizou a partir da Resolução CFB N. 406/93, os procedimentos administrativos de pedido de licença, cancelamento e pedido de suspensão.

$\mathrm{O}$ exercício da profissão de Técnico em Biblioteconomia, também é regulamentado pela Resolução CFB N. 455/98, a qual modifica a Resolução CFB N. 440/97 que dispõe sobre as atividades de técnico na área de Biblioteconomia. Para tanto, a Resolução em seu Art. 2. diz que o técnico em Biblioteconomia

[...] é todo profissional de nível médio que na esfera pública ou privada, executa os trabalhos de rotina de biblioteca, centro de documentação e/ou informação, salas de leitura, de estudo e outros espaços que tenham como suporte da informação, livros, documentos em geral e outros meios tecnológicos, visando ao tratamento, disseminação e a recuperação de informações, pesquisas e desenvolvimento. (BIBLIOTECÁRIO...,1998, p. 56).

Para a inscrição de Técnico em Biblioteconomia, o CFB, a partir da Resolução CFB n. 456/98, coloca que o exercício de Técnico "é privativo aos portadores de diplomas ou certificados de escola Técnica em Biblioteconomia e/ou na forma prevista na Resolução n. 455/98, que estejam inscritos no Conselho Regional de Biblioteconomia de sua jurisdição.” BIBLIOTECÁRIO..., 1998, p. 60).

Além das leis nacionais, existe no âmbito da Paraíba a Lei de criação do cargo de bibliotecário que está regulamentado pela Lei 3.900 de 28 de junho de 1977 e pela Lei 4.021 de 30 de novembro de 1978, onde insere o bibliotecário no grupo dos ANS (Atividades de Nível Superior) com código ANS-902. Contudo, em 2003 foi criado o Plano de Cargos Carreira e Remuneração (PCCR) de várias categorias de nível superior do estado da Paraíba, onde se inclui o quadro do profissional bibliotecário. Esta Lei garante a possibilidade de existência de concursos para a área.

No município de João Pessoa a Lei 6.885, de 10 de dezembro de 1991, sancionada pelo prefeito em exercício Carlos Alberto Pinto
Mangueira, que cria, extingue e remaneja cargos no quadro permanente de pessoal do poder executivo municipal, modifica denominações e quantitativos das tabelas constantes dos anexos à Lei n. ${ }^{\circ} 6.681$, de 29 de maio de 1991 que está respaldada na Lei ${ }^{\circ}$ 6.611 de 08 de Abril de 1991 onde especifica os grupos ocupacionais, referindo-se inclusive ao quadro permanente do serviço civil da administração direta do poder executivo municipal, dessa forma, o Art. 3 classifica os cargos de Provimento Efetivo em Comissão partir de vários grupos ocupacionais dentre eles os que realizam as Atividades de Nível Superior (ANS).

Faz-se então saber que o Estado da Paraíba e o município de João Pessoa, podem realizar concurso público para contratar bibliotecários e assumir as bibliotecas de escolas públicas, assim como de outras instituições públicas.

Vale salientar que Sousa e Santos (2009) afirmam que existem vários entraves para a efetivação da lei que cria o Sistema de Bibliotecas do Estado da Paraíba e do município de João Pessoa e que infelizmente no estado e no município após várias tentativas de Grupos de Trabalho, não existe nenhuma ação política efetiva que se ponha em prática a criação de um sistema de bibliotecas, o que possibilita o fortalecimento do mercado de trabalho.

Ressalta-se que, com a criação do Plano Nacional do Livro e Leitura (PNLL) o município de João Pessoa buscou parceria com a Universidade Federal da Paraíba (UFPB), bibliotecários organizados com os com gestores, educadores e entidades, em prol da criação de um sistema municipal de bibliotecas públicas e escolares.

Desse modo, planejar um Sistema Municipal de Bibliotecas é incluir a rede escolar e a demanda da cidade por bibliotecas públicas em um programa integrado de ações que viabilize não apenas o aporte de recursos como também sua gestão administrativa. [...] propôs a implantação de uma Biblioteca Pública Municipal Central para coordenar a implantação de pontos de leitura e bibliotecas nos bairros e nas escolas, alimentando-os e assessorando seu desenvolvimento, bem como fazendo gestão junto a Secretária de Educação e Cultura ao qual estaria vinculada a Biblioteca e o Sistema Municipal. (OLIVEIRA; SANTOS, 2011, p. 6). 


\section{Anais do Encontro Paraibano de Biblioteca Escolar}

Efetivamente o Bibliotecário e seu exercício é regulamentado por lei e é uma profissão que tem base estrutural incluindo as suas entidades de Classes como Conselho Federal, Conselhos Regionais, Federação Brasileira de Associações de Bibliotecários (FEBAB), Associações e Sindicatos. Dessa forma, esse profissional merece que seus espaços sejam preenchidos por ele, por estarem prontos legalmente e profissionalmente.

\section{DESAFIOS PARA OS BIBLIOTECÁRIOS EM BIBLIOTECAS ESCOLARES: REALIDADE DO ESTADO DA PARAÍBA E DO MUNICÍPIO DE JOÃO PESSOA}

A escola é uma instituição direcionada para receber indivíduos e dentro de sua estrutura de ensino e aprendizagem constituir cidadãos capazes de enfrentar os desafios sociais e culturais a partir da construção de seus conhecimentos.

Nesse contexto, insere-se a Biblioteca escolar como instituição mediadora neste processo, por ser a responsável em gerenciar a informação a partir de documentos impressos, especiais (multimeios), eletrônicos e digitais.

De acordo com Campello (2012) a biblioteca escolar vai muito além de um espaço de promoção de leitura, mas são também espaços de aprendizagem, dessa forma, devem ser espaços adequados para atingir esses objetivos. Afirma ainda que os bibliotecários devem estar muito atuantes as necessidades dos estudantes e das práticas estabelecidas nas escolas com vistas às atividades das bibliotecas.

A profissão de biblioteconomia passou por várias fases consideradas críticas, como o desenvolvimento de atividades extremamente técnicas em função da totalidade de serviços que constituem a profissão, como é o caso de atribuições científicas, gerenciais, culturais e humanistas. Esta postura integradora dos serviços, trouxeram para a biblioteconomia a visão de um profissional capaz de ampliar as suas atividades diante dos diferentes tipos de bibliotecas, expandido o mercado de trabalho.

Em termos teóricos, esta visão de bibliotecário qualificado em vários seguimentos atende sobremaneira a Biblioteca escolar, tendo em vista que este tipo de biblioteca é profundamente complexo diante da variedade de demanda em sua comunidade, pois abrange desde estudantes que ainda não conhecem o alfabeto até estudantes que estão em formação para o nível superior.

Nesta perspectiva, depois de muitas lutas e conquistas pela Classe bibliotecária, em 2010 é criada a Lei 12.244 que beneficia o mercado de trabalho em bibliotecas escolares. Sabendo que a obrigatoriedade de bibliotecas em instituições de ensino superior sejam elas públicas ou privadas é uma realidade desde muitos anos, a Lei 12.244/10, vislumbra novas possibilidades do bibliotecário ser reconhecido pela sociedade.

A Lei 12.244 foi sancionada pelo presidente em exercício Luiz Inácio Lula da Silva em 24 de maio de 2010, a partir do Congresso Nacional. A lei afirma a obrigatoriedade de bibliotecas em escola, incluindo sua universalização e dá um prazo de dez anos para que todas as escolas estejam dentro dos padrões estabelecidos pela lei. Contudo o Art. 1 define que: "As instituições de ensino públicas e privadas de todos os sistemas de ensino do País contarão com bibliotecas, nos termos desta Lei." No Parágrafo única do Art. 2, afirma ser obrigatório "um acervo de livros na biblioteca de, no mínimo, um título para cada aluno matriculado[...] (BRASIL, 2010).

Caminhando pela contramão, foi elaborado um Projeto de Lei da Câmara (PLC), n. 28/2012, que tem como autor o Deputado Federal Sandes Junior do Partido Progressista de Goiás, com vistas a alterar a Lei n. 9.394, de 20/12/1996 - Lei de Diretrizes e Bases da Educação Nacional (LDB), que tem como objetivo instituir a obrigatoriedade de criação e manutenção de bibliotecas escolares em todas as instituições públicas de ensino, nesta proposta, exclui a bibliotecas escolares da rede particular de ensino, deixando aberto para os diretores de escolas privadas poderem contratar um bibliotecário para desenvolver suas atividades em mais de uma biblioteca. Neste sentido, o Conselho Federal de Biblioteconomia (2012), afirma que esta PLC "além de ferir o direito de informação de toda cidadania brasileira, altera de maneira 
definitiva a Lei n.12.244/10 que se configurou em uma grande conquista para a área". Em dezembro de 2013, uma comissão do CFB esteve no Senado em reunião com o relator deste processo, o Senador Cássio Cunha Lima, para sensibilizá-lo com relação a não aprovação deste Projeto de Lei Complementar.

Recentemente, a Comissão de Educação (CE) do Senado Federal no dia 04 de setembro de 2013, concedeu parecer favorável ao substitutivo, apresentado pelo relator do processo acima citado, que corresponde à obrigatoriedade das bibliotecas em escolas particulares, reforçando também a presença nas escolas públicas. (SENADO FEDERAL, 2013 p. 7).

$\mathrm{O}$ CFB em sua página oficial (http://www.cfb.org.br/projetos.php?codigo= 20) elaborou um modelo de anteprojetos de lei de Bibliotecas Escolares Municipais e Estaduais, para serem instrumentos de apoio ao ser instituída a lei 12.244/10 em cada município.

Em busca de elevar a qualidade de bibliotecas escolares brasileiras, o Grupo (GEBE) e o CFB elaboraram um documento referencial que estabelece um padrão para bibliotecas escolares. O documento identifica nas bibliotecas escolares como sendo: "espaços de aprendizagem que propiciam e estimulam conexões entre saberes; que são laboratórios - não de equipamentos e apetrechos - mas de ideias" (BIBLIOTECA..., 2010, p. 6).

Apesar das inúmeras leis e decretos que regulamentam a importância de bibliotecas, muitas autoridades brasileiras ignoram seu papel, sendo necessária uma maior fiscalização dos órgãos responsáveis e uma lei mais rígida com caráter punitivo as esferas que não estão fazendo valer cumprir a Lei.

\section{NO CAMINHO PARA UMA CONCLUSÃO}

Ao longo do percurso histórico da Biblioteconomia no Brasil, verifica-se que existe uma relação entre a legislação do profissional em consonância com as bibliotecas. As mudanças sempre aconteceram a partir de lutas e união entre bibliotecários e sociedade.
No estado da Paraíba e em especial no município de João Pessoa, as lutas pelas entidades de classe como: Associação de Profissionais de Bibliotecários da Paraíba (APBP); Delegacia Regional (DR) do Conselho Regional de Biblioteconomia 4 Região (CRB4), instalada em João Pessoa que atuou até 2007, o Conselho Regional de Biblioteconomia 15 Região (CRB15) que passou a atuar a partir de 2007; professores da Universidade Federal da Paraíba em nome da professora Gemima Marques, entre outros profissionais, foram significativas nas conquistas da Classe até os dias atuais.

Contudo, ainda tem muito que ser realizado, sobretudo quando se trata de legislação. Neste sentido, a criação legal do Sistema de Bibliotecas Públicas e Escolares no estado da Paraíba e no município de João Pessoa, é mais um instrumento legal que fundamenta e cria a demanda no mercado de trabalho, dessa forma, os profissionais devem aproveitar o momento conjuntural que passa a área da biblioteconomia no que se refere a implantação da lei 12.244/10 no município e no estado para construir bases estruturantes no sentido da efetiva aplicabilidade desta lei.

\section{REFERÊNCIAS}

BIBLIOTECA ESCOLAR COMO ESPAÇO
DE PRODUÇÃO DO CONHECIMENTO:
parâmetros para bibliotecas escolares. GEBE,
CFB. 2010.

BIBLIOTECÁRIO E TÉCNICO EM

BIBLIOTECONOMIA: Legislação.

Conselhos Regionais de Biblioteconomia.

Recife, 1998.

BRASIL. Lei ${ }^{\circ} 10.753$, de 30 de outubro

de 2003. Institui a Política Nacional do Livro Disponível em:

<http://www.planalto.gov.br/ccivil_03/leis/20 03/110.753.htm>. Acesso em: 21 jul. 2013.

. Lei $\mathrm{n}^{0} \mathbf{1 2 . 2 4 4}$, de 24 de maio de

2010. Dispõe sobre a universalização das bibliotecas nas instituições de ensino do País. Disponível em:

<http://www.planalto.gov.br/ccivil_03/_Ato2 
007-2010/2010/Lei/L12244.htm>. Acesso em: 21 jul. 2013.

\section{Lei $\mathbf{n}^{\circ}$ 4.084, de 30 de junho de}

1962. Dispõe sobre a profissão de

bibliotecário e regula seu exercício.

Disponível em:

<https://www.planalto.gov.br/ccivil_03/Leis/

1950-1969/L4084.htm>. Acesso em: 21 jul.

2016.

Lei $\mathrm{n}^{0}$ 5.452, de 01 de maio de

1943. Aprova a Consolidação das Leis do Trabalho. Disponível em:<http://www.planalto.gov.br/ccivil_03/de creto-lei/del5452.htm>. Acesso em: 28 jul. 2016.

Lei $\mathbf{n}^{0}$ 7.504, de 02 de julho de

1986. Dispõe sobre a profissão de

bibliotecário, e dá outras providências.

Disponível

em:<http://www.planalto.gov.br/ccivil_03/lei s/L7504.htm>. Acesso em: 28 jul. 2016.

Lei no 9.764, de 25 de junho de

1998. Dispõe sobre a profissão de

bibliotecário, e determinar outras

providências. Disponível em:

<http://www.planalto.gov.br/ccivil_03/Leis/L

9674.htm>. Acesso em: 01 jul. 2016.

CAMPELLO, Bernadete (comp.) Biblioteca escolar: conhecimentos que sustentam a

prática. Minas Gerais: Autêntica, 2012.

CASTRO, César Augusto. História da

biblioteconomia brasileira: perspectiva

histórica. Brasília: Thesaurus, 2000.

CONSELHO FEDERAL DE

BIBLIOTECONOMIA. Sistema CFB/CRB.

Disponível em: <http://www.cfb.org.br/>.

Acesso em: 14 de set. 2016.

JOB, Ivone; OLIVEIRA, Dalgiza Andrade.

Marcos históricos e legais do

desenvolvimento da profissão de bibliotecário no Brasil. Revista ABC, v. 11, n. 2, 2006.

Disponível em:

$<$ http://revista.acbsc.org.br/racb/article/view/4

49/565>. Acesso em: 10 ago. 2016.
SOUSA, Beatriz Alves de; SANTOS, Edilene

Toscano G. dos; Bibliotecas públicas estruturadas: o primeiro passo rumo á democratização da informação. In: CONGRESSO BRASILEIRO DE BIBLIOTECONOMIA, DOCUMENTAÇÃO E CIÊNCIA DA INFORMAÇÃO, 23.

Anais... Bonito: FEBAB, 2009.

OLIVEIRA, Jemima Marques; SANTOS, Edilene Toscano G. dos; As aspirações e a realidade das políticas públicas para a biblioteca no Brasil: o caso Paraíba. In: CONGRESSO BRASILEIRO DE BIBLIOTECONOMIA, DOCUMENTAÇÃO E CIÊNCIA DA INFORMAÇÃO, 24.

Sistemas de Informação, Multiculturalidade e Inclusão Social. Anais... Maceió: CBBD, 2011. p. 1-9.

SANTOS, Josiel Machado. Bibliotecas no Brasil: um olhar histórico. Revista Brasileira de Biblioteconomia e Documentação. São Paulo, v. 6, n. 1, p. 50-61, jan./jun., 2010.

SENADO FEDERAL. Projeto que obriga colégio ...Jornal do Senado, Brasília, 4 set. 2013. Ano 19, no 3.941, p.7. Disponível em: $<$ http://www12.senado.gov.br $>$ Acesso em: 08 set.2016. 